\title{
EFICACIA ANTIBACTERIANA DE EXTRACTOS DE PLANTAS: APLICACIÓN CLÍNICA EN MASTITIS BOVINA
}

\section{ANTIBACTERIAL EFFICACY OF PLANT EXTRACTS: CLINICAL APPLICATION IN BOVINE MASTITIS}

\author{
Marco Leal ${ }^{1}$
}

${ }^{1}$ MV. M.Sc. Docente Investigador. Facultad de Ciencias Pecuarias. Universidad de Ciencias Aplicadas y Ambientales. U.D.C.A. Bogotá, Colombia. Calle 222 No. 55-37. Correo: mleal@udca.edu.co

Rev. U.D.CA Act. \& Div. Cient. 17(1): 179-187, Enero-Junio, 2014

\section{RESUMEN}

La mastitis en los bovinos es una enfermedad que afecta la calidad y la cantidad de la leche, teniendo un impacto directo sobre la salud pública. Muchos tratamientos han sido utilizados, con el fin de disminuir la inflamación y la infección, causados por este problema; sin embargo, la utilización de casi todos los fármacos conlleva a residuos en la leche. Se evaluaron extractos fitoterapéuticos, con capacidad antibacteriana reportada, contra tres bacterias causantes de mastitis, Staphylococcus aureus, Streptococcus agalactiae y Escherichia coli. Los extractos empleados fueron obtenidos de Thymus vulgaris, Calendula officinalis y Salvia officinalis. Los hallazgos in vitro revelaron efecto bactericida con C. officinalis, en diluciones $1 / 2,1 / 4$ y $1: 8$, en comparación con un efecto bactericida de los otros extractos, en las dos primeras diluciones. Con el grupo control con vehículo de propilenglicol, se obtuvo un menor efecto bactericida. Con base en los efectos in vitro, se intentó disminuir las células somáticas en bovinos con mastitis diagnosticada. Los resultados en los grupos tratados fueron en promedio un $23 \%$ de tasa de curación de los cuartos infectados. Se obtuvieron reacciones adversas en el $60 \%$ de los cuartos tratados. Con lo anterior, se concluyó que, a pesar de existir un comportamiento bactericida in vitro, no se puede asegurar que se obtendrán resultados antiinflamatorios en la glándula mamaria y que las reacciones adversas a la mezcla de extractos se deben más al uso per se de los extractos que al vehículo, tomando en cuenta que el propilenglicol es un vehículo común de preparaciones farmacéuticas tópicas y parenterales.

Palabras clave: Caléndula, tomillo, salvia, antibióticos, antiinflamatorio.
SUMMARY

Mastitis in cattle is a disease that affects the quality and quantity of milk, having a direct impact on public health. Many treatments have been used to reduce inflammation and infection caused by this problem. However, the use of almost all drugs needs a withdrawal time. Using herbal extracts with reported antibacterial capacity, were used against three common mastitis-causing bacteria, Staphylococcus aureus, Streptococcus agalactiae and Escherichia coli. Extracts of Thymus vulgaris, Calendula officinalis and Salvia officinalis were evaluated. In vitro findings revealed bactericidal effect in all dilutions of $C$. officinalis $1 / 2,1 / 4$ and $1: 8$, as compared with the bactericidal effect of other extracts in the first two dilutions. Control group using propylene glycol demonstrated lower bactericidal effect. Based on these in vitro effects minimization of somatic cell count in bovine mastitis was attempted. The results in the treated groups were of an average of $23 \%$ cure rate of infected quarters. Adverse reactions were obtained in $60 \%$ of treated quarters. With the above it was conclude that the behavior of the extracts in vitro and in vivo is different. Adverse reactions to the mixture of extracts apparently were not due to the vehicle, taking into account that propylene glycol is a common vehicle for topical and parenteral pharmaceutical preparations.

Key words: Calendula officinalis, Thymus vulgaris, Salvia officinalis, anti-inflammatory, antibiotic, cow mastitis.

\section{INTRODUCCIÓN}

La mastitis bovina es una de las enfermedades que mayor impacto produce sobre la producción láctea, generando pérdidas económicas, que son variables y que aumentan a medida que los recuentos de células somáticas son más al- 
tos. En Colombia, por ejemplo, existe un estudio que revela pérdidas por, aproximadamente, 170 dólares por lactancia de 300 días (Rodríguez, 2006). En países de Europa, como Portugal, se ha calculado que por cada animal que recibe medicación antibiótica contra mastitis, las pérdidas por trimestre son de 38 Euros. Lo anterior para mastitis subclínicas; para el caso de mastitis clínicas, se reportan pérdidas en la producción de más de 700L de leche por lactancia en Norteamérica (Seegers et al. 2003). En un estudio realizado por Santos et al. 2003, se explica que los conteos de células somáticas tienen relación directa con cambios en la composición de la leche, mencionando que un conteo superior a 200,000 células/mL produce mayores alteraciones en las características químicas de la leche, en comparación con conteos inferiores a este número.

La mastitis, se desarrolla cuando, por múltiples razones, los mecanismos de defensa de la glándula mamaria se encuentran alterados. Inicialmente, la glándula mamaria es capaz de resistir a la infección sin la asistencia del sistema inmune, mediante la participación de la queratina, presente en los ductos del pezón (función de barrera), la alta capacidad de adherencia de los microorganismos a la mucosa regional y la lactoperoxidasa, una enzima en la leche, cuyas propiedades inhiben el crecimiento bacteriano (FAO, 2005). Además, el sistema de protección lo complementan la inmunidad humoral y la inmunidad mediada por células, en donde participan inmunoglobulinas y glóbulos blancos, respectivamente.

La enfermedad puede tener su origen en traumatismos o, como es más común, cuando alguno de los mecanismos mencionados falla; es posible que la glándula sea colonizada por alguno de los principales agentes etiológicos de la enfermedad, (Staphylococcus aureus, Streptococcus spp., Escherichia coli, Mycoplasma bovis, entre otras). En cuanto a la clasificación, la enfermedad se puede catalogar de acuerdo a su severidad, el grado de afectación de la glándula y el tiempo de evolución, pudiendo presentarse diferentes grados de mastitis (Bradford, 2009), de la siguiente manera: Cuartos negativos, Cuartos con trazas, Cuartos con mastitis subclínica 1, Cuartos con mastitis subclínica 2 y Cuartos con mastitis subclínica 3 .

Los antibióticos cuando son administrados vía intramamaria ocasionan residuos en leche, que son un problema de salud pública, porque pueden producir resistencias en los seres humanos.

En los últimos años ha cobrado interés el uso de fitoterapéuticos para aplicación intramamaria y, a pesar de requerir aún estudios más avanzados de eficacia, como lo sugiere Regassa \& Araya (2012), pueden ser eficaces a la hora de reducir las pérdidas de leche provocadas por el uso de antibióticos.
A continuación, se presentan características de las plantas que fueron evaluadas durante el estudio:

Salvia officinalis: Nombre común: salvia: Es una planta que contiene, principalmente, terpenoides (Climati et al. 2013) y flavonoides (Ravipati et al. 2012), con acciones aromáticas, utilizada como astringente, antimicrobiano y desinfectantes (Cañigueral, 2003). La salvia es un género de plantas de la familia Lamiaceae y de ella, existen alrededor de 900 especies, siendo la más estudiada la S. officinalis, entre otras, por sus propiedades antibacterianas contra Bacillus cereus y otros microorganismos (Climati et al. 2013); incluso, Shahneh et al. (2013), ha propuesto actividad citotóxica en cultivos de células cancerosas humanas; sin embargo, en ninguno de los fitoterapéuticos utilizados en este trabajo, no se conocen las dosis que tengan un efecto antibacteriano.

Thymus vulgaris: Nombre común Tomillo: Las plantas del género Thymus, contienen acetato bornílico, acetato linalico, saponinas y flavoniodes (Hossain et al. (2013) y pertenece a un grupo de plantas con capacidades antisépticas (Wei et al. 2014) y antifúngicas, usualmente, utilizada en la piel. También contiene compuestos fenólicos, timol y carvacrol, los cuales, poseen actividad frente a bacterias gram positivas y negativas, debido a que estas sustancias actúan sobre la membrana celular bacteriana. El extracto de tomillo inhibe, en forma significativa, el crecimiento de Helicobacter pilori (Esmaeili et al. 2012).

Calendula officinalis: Nombre común: Caléndula: Pertenece a un género con gran cantidad de especies perennes de la familia Asteraceae. Esta planta posee, entre otras sustancias, flavonoides, triterpenos, taninos y compuestos fenólicos (Preethi \& Kuttan, 2009), que le confieren propiedades cicatrizantes, antiinflamatorias e, incluso, antibacterianas. Se utiliza comúnmente en terapias, como la cicatrización de heridas (Tanideh et al. 2013) o como antioxidante (Shivasharan et al. 2013).

\section{MATERIALES Y MÉTODOS}

Inicialmente, se tomaron extractos vegetales de T. vulgaris, S. officinalis y C. officinalis, fabricados por Laboratorios Phitother, S.A, fabricados a partir de hojas secas y maceradas de cada una de las plantas y posteriormente solubilizadas en etanol al 90\%, utilizando un rotovapor. Con estos extractos, se hicieron pruebas antibacterianas en caja de Petri, contra diferentes microorganismos. De igual forma, se utilizó, a manera de control, el vehículo utilizado en cada uno de los extractos (propilenglicol). Se escogió este vehículo por ser de uso común en preparaciones tópicas y sobre mucosas. Todos los extractos, previamente, fueron evaluados para establecer la ausencia de contaminación bacteriana por $E$. coli, Coliformes totales, mesófilos, mohos y levaduras, en- 
contrando los siguientes resultados: $E$. coli y coliformes: Ausencia; Mesófilos aerobios: <10ufc/g, cumpliendo con la especificación que indica que debe ser menor a 100ufc/g; mohos y levaduras: $<10 \mathrm{ufc} / \mathrm{g}$, cumpliendo con la especificación que indica que debe ser menor o igual a 10ufc/g.

Se realizaron evaluaciones microbiológicas a los extractos de caléndula, tomillo, salvia y propilenglicol, como vehículo para determinar su efecto antimicrobiano (grupo control). El estudio, se realizó utilizando los siguientes microorganismos: S. aureus ATCC 25923, E. coli ATCC 25922 y S. agalactiae, para los que se usó una suspensión 0,5 en la escala de Mc Farland, equivalente a una suspensión bacteriana de 1,5 $\mathrm{x}$ $10^{8} \mathrm{UFC} / \mathrm{mL}$.

Cada uno de las bacterias fue desafiada con diferentes proporciones de los extractos de la siguiente manera: 1:2, $1: 4,1: 8$.

Medio de cultivo: Caldo Tripticasa de soya marca Oxoid, doble concentración, para la primera proporción y concentra- ción normal, para las otras diluciones. Medio sólido: Agar Tripticasa de Soya marca Merck, para evidenciar crecimiento, con Método Ecométrico (Prescott, 2008).

Para evidenciar si hubo o no crecimiento en las diluciones y en el control de cada microorganismo, se sembraron con asa calibrada $10 \mu \mathrm{L}$ sobre una placa de agar Tripticasa de soya, para $S$. aureus y $E$. coli y sobre agar sangre, para $S$. agalactiae, haciendo cinco trazados por proporción, como recomienda el Método Ecométrico (Koneman, 2008). Las cajas, se incubaron a $37^{\circ} \mathrm{C}$ incubación, por 24 horas; los cultivos fueron realizados por duplicado. En cuanto a la prueba ecométrica, se emplea un esquema de siembra, en donde se asigna un número por cada línea de crecimiento bacteriano del 1 al 5. La porción superior marcada con el número 1 representa el sector en donde es aplicado el extracto en proporción 1:2. La parte derecha, marcada con el número 2, indica el lugar en donde se aplica el extracto en proporción 1:4. La inferior muestra el lugar en donde se coloca el extracto $1: 8$ y la parte izquierda, marcada con el número 4 , indica el lugar del control (Figura 1).

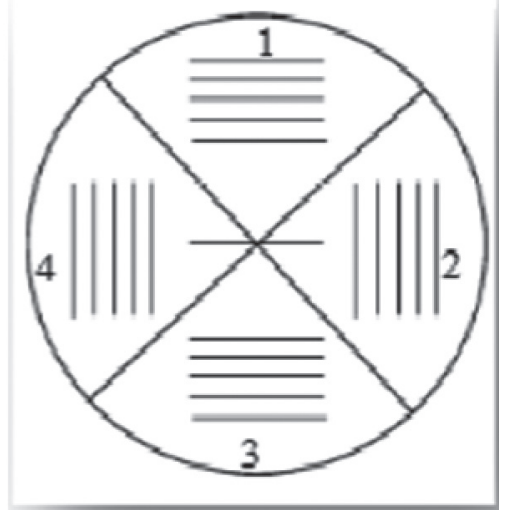

Figura 1. Método Ecométrico utilizado durante las pruebas de eficacia antibacteriana de cada uno de los extractos.

La prueba clínica en bovinos con mastitis fue aprobado por el Comité de Ética en Investigación de la Universidad de Ciencias Aplicadas y Ambientales U.D.C.A, en su sesión ordinaria del 21 de febrero de 2012, según consta en el acta No. 14. Inicialmente, se tomaron un total de 4 cuartos sanos (sin evidencia clínica de mastitis), en los que se llevó a cabo una prueba con la mezcla de extractos vegetales, a manera de prueba piloto; posteriormente, se tomaron 30 cuartos con evidencia clínica de inflamación y confirmación, mediante pruebas de Mastitis, California Mastitis Test (Deb \& Kumar, 2013). Se utilizaron los bovinos que, en la prueba CMT, arrojaron resultados iguales o superiores a grados 1 o 2 . En estos cuartos fue aplicada la mezcla de extractos naturales cada 24 horas, durante 3 días. Previamente, fueron tomadas muestras para realizar los conteos de células somáticas individua- les por cuarto y realizar un cultivo microbiológico, con el fin de determinar la presencia de agentes infecciosos. Muestras comparativas fueron tomadas 10 días después de iniciado el tratamiento.

Análisis estadístico: Para poder establecer si existió diferencia estadísticamente significativa en los conteos de células somáticas antes y después del tratamiento, se realizó la prueba de comparación de medias vía t student.

Para comparar el efecto positivo o negativo del tratamiento aplicado sobre los grados de mastitis detectados con california mastitis test, se utilizó el método no paramétrico, conocido como prueba de signos. 


\section{RESULTADOS Y DISCUSIÓN}

En la fase inicial del estudio, se revisaron los resultados de la inhibición del crecimiento bacteriano encontrando efectos de los extractos sobre $S$. aureus, de la siguiente manera (Figura 2a, Tabla 1).

El extracto de $C$. officinalis posee efecto bactericida total en todas las diluciones. El grupo control sin extracto de caléndula, en cambio, no presentó ningún efecto y el crecimiento bacteriano pudo ser evidenciado. El extracto de T. vulgaris produjo resultados bactericidas, principalmente, en las diluciones 1:2 y 1:4; en el grupo control no se observaron efectos bactericidas. El extracto de S. officinalis produjo resultados bactericidas, principalmente, en las diluciones $1: 2$ y 1:4; en el grupo control, no se observaron efectos bactericidas. Por su parte, el propilenglicol demostró también efectos bactericidas, aunque inferiores a los observados con los extractos. a

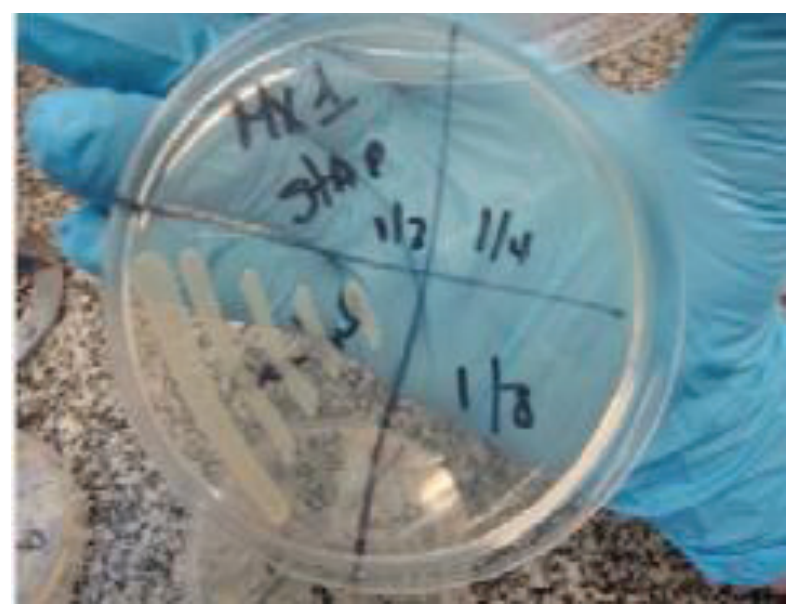

b

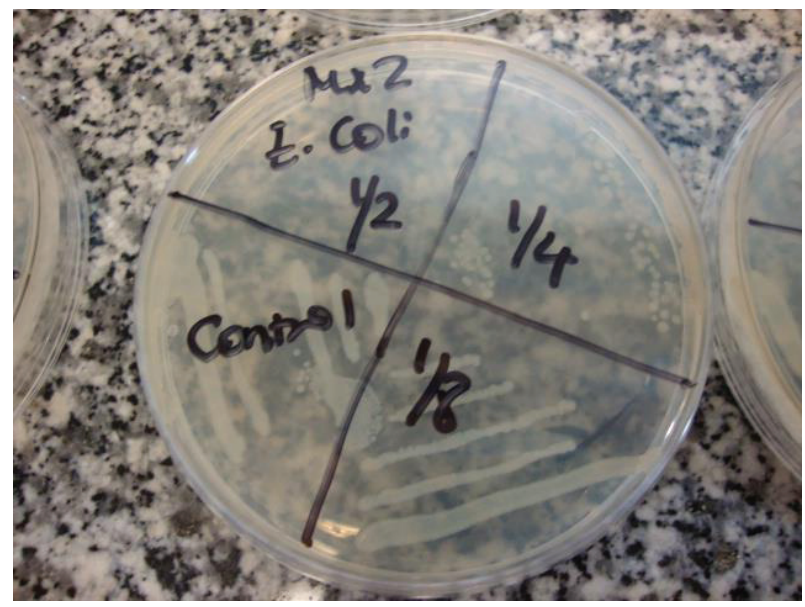

C

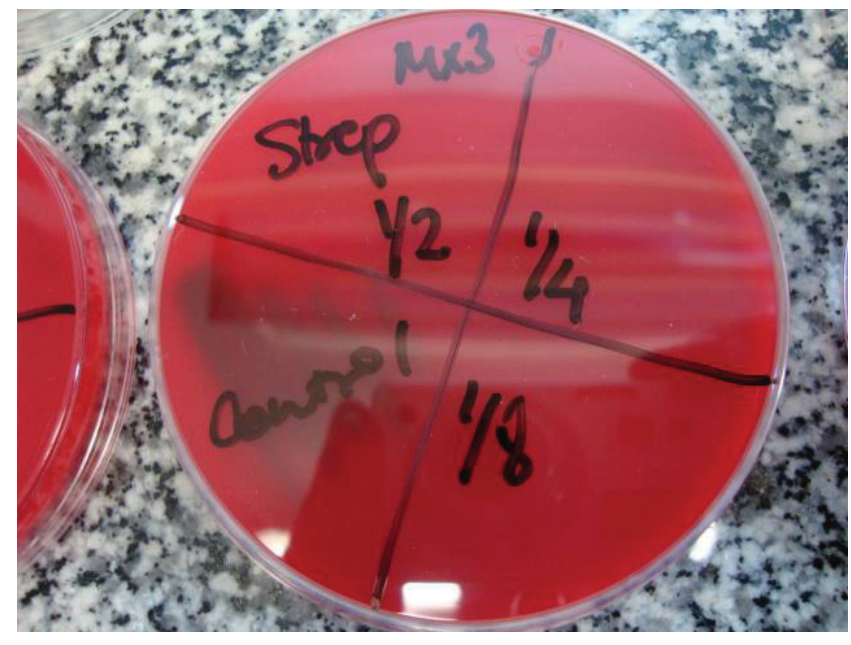

Figura 2. a) Sensibilidad de Staphylococcus aureus en la prueba microbiológica; b) Representa la ausencia de crecimiento bacteriano (E. coli); c) Representa la ausencia de crecimiento bacteriano (S. agalactiae). 
Tabla 1. Sensibilidad de Staphylococcus aureus frente a los diferentes extractos.

\begin{tabular}{|c|c|c|c|c|c|}
\hline Montaje & $\begin{array}{c}\text { Proporción o } \\
\text { dilución }\end{array}$ & $\begin{array}{l}\text { Extracto de } \\
\text { Caléndula }\end{array}$ & $\begin{array}{l}\text { Extracto de } \\
\text { Tomillo }\end{array}$ & $\begin{array}{l}\text { Extracto de } \\
\text { Salvia }\end{array}$ & $\begin{array}{c}\text { Vehículo } \\
\text { Propilenglicol }\end{array}$ \\
\hline \multirow[t]{4}{*}{1} & $1: 2$ & 0 & 0 & 0 & 5 \\
\hline & $1: 4$ & 0 & 0 & 0 & 5 \\
\hline & $1: 8$ & 0 & 2 & 1 & 5 \\
\hline & Control & 5 & 5 & 5 & 5 \\
\hline \multirow[t]{4}{*}{2} & $1: 2$ & 0 & 2 & 0 & 2 \\
\hline & $1: 4$ & 0 & 4 & 0 & 4 \\
\hline & $1: 8$ & 1 & 5 & 5 & 5 \\
\hline & Control & 5 & 5 & 5 & 5 \\
\hline \multirow[t]{4}{*}{3} & $1: 2$ & 0 & 0 & 0 & 1 \\
\hline & $1: 4$ & 0 & 3 & 0 & 3 \\
\hline & $1: 8$ & 0 & 5 & 3 & 5 \\
\hline & Control & 5 & 5 & 5 & 5 \\
\hline
\end{tabular}

Criterios de interpretación:

Calificación 0: se interpreta como efecto bactericida de $100 \%$.

Calificación 1: crecimiento en la primera línea de siembra que se interpreta como un efecto bacteriano parcial, aproximadamente sobre el $80 \%$ de la población.

Calificación 2, 3 y 4: crecimiento en las líneas 2, 3 y 4 se interpreta como efecto bactericida sobre un $60 \%, 40 \%$ y $20 \%$ de la población, respectivamente.

Calificación 5: crecimiento en las 5 líneas igual al control y se interpreta como ningún efecto bactericida.

En cuanto a los efectos de los extractos sobre E. coli, se observó que el extracto de $C$. officinalis posee efecto bactericida en las diluciones 1:2 y 1:4. El grupo control sin extracto de caléndula, en cambio, no presentó ningún efecto y el crecimiento bacteriano pudo ser evidenciado. El extracto de T. vulgaris produjo resultados bactericidas, principalmente, en la proporción 1:2; en el grupo control, no se observaron efectos bactericidas. El extracto de S. officinalis produjo resultados bactericidas, principalmente, en la proporción 1:2; en el grupo control, no se observaron efectos bactericidas. El propilenglicol demostró también efectos bactericidas, aunque inferiores a los observados con los extractos (Figura $2 b$, Tabla 2).

Por su parte, los efectos de los extractos sobre S. agalactiae fueron los siguientes: El extracto de C. officinalis posee efecto bactericida en las diluciones 1:2 y 1:4. El grupo control sin extracto de caléndula, en cambio, no presentó ningún efecto y el crecimiento bacteriano pudo ser evidenciado. El extracto de T. vulgaris produjo resultados bactericidas, principalmente, en las diluciones 1:2 y 1:4; en el grupo control, no se observaron efectos bactericidas. El extracto de S. officinalis produjo resultados bactericidas totales en todas las dilucio- nes; en el grupo control, no se observaron efectos bactericidas. El propilenglicol demostró también efectos bactericidas, aunque inferiores a los observados con los extractos (Figura 2c, Tabla 3).

Cuando se aplicaron por vía intramamaria los extractos en proporción 1:4 a razón de $3 \mathrm{ml}$ por cada cuarto, se encontró que los primeros cuatro tratados, con la mezcla de extractos naturales, no desarrollaron ningún tipo de reacción adversa. Cabe mencionar, que dichos cuartos se encontraban sanos, es decir, sin evidencia de Mastitis durante las pruebas de California (CMT). Estos cuartos no fueron muestreados para pruebas microbiológicas; sin embargo, no arrojaron resultados sugerentes de mastitis en las pruebas CMT. Los resultados de los 30 cuartos tratados se presentan en la tabla 4.

De los 30 cuartos tratados con la mezcla, 8 disminuyeron significativamente el grado de mastitis $(26,7 \%)$, de acuerdo al test de California y al conteo de células somáticas; no obstante, los 22 cuartos restantes $(73,3 \%)$ elevaron el recuento de células somáticas, así como el grado de mastitis, incluso, en algunos casos que fueron inicialmente registrados como mastitis sub-clínica, a partir de la aplicación del producto, 
desarrollaron un cuadro inflamatorio agudo, caracterizado por tumefacción del pezón y de la glándula mamaria, elevación local de la temperatura y pérdida de la calidad de la leche, caracterizada por evidencia de coágulos lácteos y coloración ligeramente amarilla. Lo anterior fue registrado durante el estudio, como una reacción adversa no esperada, ya que las pruebas iniciales en animales sanos no presen- taron ningún tipo de signo similar. Es necesario mencionar que los extractos utilizados poseían un certificado de calidad que incluía la ausencia de contaminación, que pudiera haber ocasionado la reacción.

Adicionalmente, de los 30 cuartos tratados como grupo control (solución salina + caléndula en medio acuoso), siete

Tabla 2. Sensibilidad de Escherichia coli frente a los diferentes extractos.

\begin{tabular}{|c|c|c|c|c|c|}
\hline \multirow{3}{*}{ Montaje } & $\begin{array}{c}\text { Proporción o } \\
\text { dilución }\end{array}$ & $\begin{array}{c}\text { Extracto de } \\
\text { Caléndula }\end{array}$ & $\begin{array}{c}\text { Extracto de } \\
\text { Tomillo }\end{array}$ & $\begin{array}{c}\text { Extracto de } \\
\text { Salvia }\end{array}$ & $\begin{array}{c}\text { Vehículo } \\
\text { Propilenglicol }\end{array}$ \\
\hline \multirow{4}{*}{1} & $\mathbf{1 : 2}$ & 0 & 0 & 0 & 0 \\
\cline { 2 - 6 } & $\mathbf{1 : 4}$ & 0 & 2 & 5 & 5 \\
\cline { 2 - 6 } & $\mathbf{1 : 8}$ & 5 & 5 & 5 & 5 \\
\hline \multirow{4}{*}{2} & Control & 5 & 5 & 5 & 5 \\
\cline { 2 - 6 } & $\mathbf{1 : 2}$ & 0 & 3 & 0 & 0 \\
\cline { 2 - 6 } & $\mathbf{1 : 4}$ & 0 & 5 & 1 & 1 \\
\cline { 2 - 6 } & $\mathbf{1 : 8}$ & 5 & 5 & 5 & 5 \\
\hline \multirow{3}{*}{3} & Control & 5 & 5 & 0 & 5 \\
\cline { 2 - 6 } & $\mathbf{1 : 2}$ & 0 & 0 & 3 & 2 \\
\cline { 2 - 6 } & $\mathbf{1 : 4}$ & 0 & 5 & 5 & 5 \\
\cline { 2 - 6 } & $\mathbf{1 : 8}$ & 5 & 5 & 5 & 5 \\
\hline
\end{tabular}

Tabla 3. Comportamiento de Streptococcus agalactiae frente a los diferentes extractos.

\begin{tabular}{|c|c|c|c|c|c|}
\hline \multirow{3}{*}{ Montaje } & $\begin{array}{c}\text { Proporción o } \\
\text { dilución }\end{array}$ & $\begin{array}{c}\text { Extracto de } \\
\text { Caléndula }\end{array}$ & $\begin{array}{c}\text { Extracto de } \\
\text { Tomillo }\end{array}$ & $\begin{array}{c}\text { Extracto de } \\
\text { Salvia }\end{array}$ & $\begin{array}{c}\text { Vehículo } \\
\text { Propilenglicol }\end{array}$ \\
\hline \multirow{4}{*}{1} & $\mathbf{1 : 2}$ & 0 & 0 & 0 & 0 \\
\cline { 2 - 6 } & $\mathbf{1 : 4}$ & 0 & 0 & 0 & 3 \\
\cline { 2 - 6 } & $\mathbf{1 : 8}$ & 1 & 1 & 0 & 5 \\
\hline \multirow{4}{*}{2} & Control & 5 & 5 & 5 & 5 \\
\cline { 2 - 6 } & $1: 2$ & 0 & 2 & 0 & 0 \\
\cline { 2 - 6 } & $1: 4$ & 0 & 3 & 0 & 1 \\
\cline { 2 - 6 } & $\mathbf{1 : 8}$ & 5 & 5 & 0 & 5 \\
\hline \multirow{4}{*}{3} & Control & 5 & 5 & 5 & 5 \\
\cline { 2 - 6 } & $1: 2$ & 0 & 0 & 0 & 3 \\
\cline { 2 - 6 } & $1: 4$ & 0 & 2 & 0 & 5 \\
\cline { 2 - 6 } & Control & 5 & 5 & 5 & 5 \\
\hline
\end{tabular}


Tabla 4. Conteos de células somáticas (CCS) y grados de mastitis antes y después del tratamiento (CMT: prueba de California).

\begin{tabular}{|c|c|c|c|c|}
\hline $\begin{array}{c}\text { IDENTIFICACIÓN } \\
\text { CUARTO }\end{array}$ & CCS INICIO & $\begin{array}{c}\text { GRADO } \\
\text { INICIAL CMT }\end{array}$ & CCS FIN & $\begin{array}{c}\text { GRADO FINAL } \\
\text { CMT }\end{array}$ \\
\hline 7812 & 2.846 .000 & 2 & 2.813 .000 & 2 \\
\hline 5434 & 191.000 & 1 & 4.219 .000 & 3 \\
\hline 7240 ad & 560.000 & 1 & 1.605 .000 & 2 \\
\hline 4002 PD & 639.000 & 1 & 54.000 & TRAZAS \\
\hline $4202 \mathrm{AD}$ & 257.000 & 1 & 1.317 .000 & 2 \\
\hline 7864 PI & 237.000 & 1 & 351.000 & 2 \\
\hline 7864 AD & 276.000 & 1 & 363.000 & 1 \\
\hline $7864 \mathrm{AI}$ & 356.000 & 1 & 568.000 & 1 \\
\hline $4684 \mathrm{PI}$ & 207.000 & 1 & 1.245 .000 & 2 \\
\hline 4684 PD & 650.000 & 1 & 1.342 .000 & 2 \\
\hline 1397 PD & 1.494 .000 & 2 & 3.911 .000 & 3 \\
\hline $1397 \mathrm{AD}$ & 1.000 .000 & 2 & 3.978 .000 & 3 \\
\hline 5157 PD & 286.000 & 1 & 2.699 .000 & 3 \\
\hline 5157 AD & 714.000 & 2 & 1.525 .000 & 2 \\
\hline $5165 \mathrm{AD}$ & 1.622 .000 & 2 & 3.767 .000 & 3 \\
\hline 5165 PD & 3.850 .000 & 3 & 2.361 .000 & 2 \\
\hline 4208 AD & 3.261 .000 & 3 & 1.317 .000 & 2 \\
\hline 1004AD & 1.090 .000 & 2 & 3.711 .000 & 3 \\
\hline $421 \mathrm{AI}$ & 407.000 & 1 & 318.000 & 1 \\
\hline 279 PI & 483.000 & 1 & 4.677 .000 & 3 \\
\hline $1078 \mathrm{AI}$ & 263.000 & 1 & 4.290 .000 & 3 \\
\hline 359 AD & 1.711 .000 & 2 & 418.000 & 1 \\
\hline 7544 AD & 418.000 & 1 & 4.636 .000 & 3 \\
\hline 68 PD & 561.000 & 1 & 4.978 .000 & 3 \\
\hline 5508 PD & 500.000 & 1 & 591.000 & 1 \\
\hline 5508 AI & 1.060 .000 & 2 & 637.000 & 1 \\
\hline 421000 & 1.085 .000 & 2 & 435.000 & 1 \\
\hline 7544 PD & 315.000 & 1 & 387.000 & 1 \\
\hline 7544 PI & 2.284 .000 & 2 & 581.000 & 1 \\
\hline 7543 AD & 1.327 .000 & 2 & 3.264 .000 & 3 \\
\hline
\end{tabular}

disminuyeron el grado de mastitis, de acuerdo al test de California y al conteo de células somáticas; sin embargo, los 23 cuartos restantes elevaron el recuento de células somáticas, sin presentar elevaciones significativas en el grado de mastitis, de acuerdo a la prueba de California. De los 30 cuartos del grupo control, cuatro de ellos manifestó los signos de rubor, de calor y de tumefacción, así como la pérdida de la calidad de la leche, registrados para los animales del grupo tratado.

El valor de la prueba estadística de signos para establecer la eficacia del tratamiento en disminuir el grado de mastitis, de acuerdo al CMT, fue de $0.0106(\mathrm{P}=0.0106)$, por lo tanto, se puede inferir que el tratamiento no fue eficaz. 
Para poder establecer si existió diferencia estadísticamente significativa en los conteos de células somáticas antes y después del tratamiento, se realizó la prueba de comparación de medias vía t student, con un valor de p de 0.004038203 , con lo cual, se puede inferir diferencia estadísticamente significativa entre las medias, concluyendo que el tratamiento no fue eficaz.

Pruebas exclusivas con el vehículo propilenglicol: reacciones adversas similares a las observadas durante el estudio, pero en menor grado que las observadas con los extractos.

Teniendo en cuenta los efectos observados en los animales tratados y del grupo control, se concluyó que el comportamiento de los extractos in vitro e in vivo es diferente, ya que en realidad no disminuyen los efectos inflamatorios en la glándula mamaria, diagnosticada con mastitis. Por su parte, las reacciones adversas a la mezcla de extractos se deben más al uso per se de los extractos que al vehículo, tomando en cuenta que el propilenglicol es un vehículo común de preparaciones farmacéuticas tópicas y parenterales.

De todo lo anterior, también se deduce que la utilización de extractos naturales de eficacia in vitro comprobada, no generó resultados satisfactorios in vivo, cuando fue aplicada en bovinos con mastitis de etiología infecciosa. Asimismo, se pudo establecer que in vivo, las combinaciones de extractos, no son lo suficientemente eficaces para corregir el problema y que, incluso, se pueden encontrar reacciones adversas que no se deben al vehículo (propilenglicol). Es posible que los extractos, a pesar de ser aplicados en proporción, produzcan irritación e inflamación, lo que exacerba los síntomas de la mastitis. Este efecto es esperado cuando se usan terapias homeopáticas, aunque no con la magnitud observada en el presente estudio.

Conflicto de intereses: El presente trabajo fue preparado por el autor, quien declara que no existe conflicto de intereses que ponga en riesgo la validez de los resultados o la voluntad de publicación de los mismos. Financiación: Este estudio fue financiado por la Universidad de Ciencias Aplicadas y Ambientales U.D.C.A.

\section{BIBLIOGRAFÍA}

1. BRADFORD, P. 2009 Large Animal Internal Medicine. Fourth Edition. Elsevier. 1872p.

2. CAÑIGUERAL, S. 2003. Fitoterapia, Vademécum de prescripción. Plantas Medicinales, Masson SA. Barcelona España. 1092p.

3. CLIMATI, E.; MASTROGIOVANNI, F.; VALERI, M.; SALVINI, L.; BONECHI, C.; MAMADALIEVA, N.Z.; EGAM-
BERDIEVA, D.; TADDEI, A.R., TIEZZI, A. 2013. Methyl carnosate, an antibacterial diterpene isolated from Salvia officinalis leaves. Nat. Prod Commun. 8(4):429-430.

4. DEB, R.; KUMAR, A. 2013. Trends in diagnosis and control of bovine mastitis: a review. Pak. J. Biol. Sci. 16(23):1653-1661.

5. ESMAEILI, D.; MOBAREZ, A.M.; TOHIDPOUR, A. 2012. Anti-helicobacter pylori activities of shoya powder and essential oils of Thymus vulgaris and Eucalyptus globulus. Open Microbiol. J. 6:65-69.

6. FOOD AND AGRICULTURE ORGANIZATION OF THE UNITED NATIONS, FAO. 2005. Benefits and potential risks of the lactoperoxidase system of raw milk preservation. Report of FAO/WHO Technical Meeting, Rome, 28 November to 2 December. Disponible desde Internet en: ftp://ftp.fao.org/docrep/fao/009/ a0729e/a0729e00.pdf (con acceso 09/04/2012).

7. HOSSAIN, M.A.; AL-RAQMI, K.A.; AL-MIJIZY, Z.H.; WELI, A.M.; AL-RIYAMI, Q. 2013. Study of total phenol, flavonoids contents and phytochemical screening of various leaves crude extracts of locally grown Thymus vulgaris. Asian. Pac. J. Trop. Biomed. 3(9):705710.

8. KONEMAN, E. 2008. MIcrobiological diagnosis. Text and color atlas. Editorial Médica Panamericana. 1691p.

9. PRESCOTT, H. 2008. Microbiología. 7a Edición. Editorial Mac Graw Hill Interamericana de España. 1124p.

10. PREETHI, K.C.; KUTTAN, R. 2009. Wound healing activity of flower extract of Calendula officinalis. J. Basic Clin. Physiol. Pharmacol. 20(1):73-79.

11. RAVIPATI, A.S.; ZHANG, L.; KOYYALAMUDI, S.R.; JEONG, S.C.; REDDY, N.; BARTLETT, J.; SMITH, P.T.; SHANMUGAM, K.; MÜNCH, G.; WU, M.J.; SATYANARAYANAN, M.; VYSETTI, B. 2012. Antioxidant and anti-inflammatory activities of selected Chinese medicinal plants and their relation with antioxidant content. BMC Complement Altern. Med. 12:173.

12. REGASSA, F.; ARAYA, M. 2012. In vitro antimicrobial activity of Combretum molle (Combretaceae) against Staphylococcus aureus and Streptococcus agalactiae isolated from crossbred dairy cows with clinical mastitis. Trop. Anim. Health. Prod. 44(6):1169-1173. 
13. RODRÍGUEZ, G. 2006. Comportamiento de la mastitis bovina y su impacto económico en algunos hatos de la Sabana de Bogotá, Colombia. Rev Med Vet. 12:35-45.

14. SANTOS, M.V.; MA, Y.; BARBANO, D.M. 2003. Effect of somatic cell count on proteolysis and lipolysis in pasteurized fluid milk during shelf-life storage. J. Dairy Sci. 86(8):2491-2503.

15. SEEGERS, H.; FOURICHON, C.; BEAUDEAU, F. 2003. Production effects related to mastitis and mastitis economics in dairy cattle herds. Vet. Res. 34(5):475491.

16. SHAHNEH, F.; VALIYARI, S.; BARADARAN, B.; ABDOLALIZADEH, J.; BANDEHAGH, A.; AZADMEHR, A.; HAJIAGHAEE, R. 2013. Inhibitory and cytotoxic activities of Salvia officinalis L. extract on human lymphoma and leukemia cells by induction of apoptosis. Adv. Pharm. Bull. 3(1):51-55.
17. SHIVASHARAN, B.D.; NAGAKANNAN, P.; THIPPESWAMY, B.S.; VEERAPUR, V.P. 2013. Protective effect of Calendula officinalis L. flowers against monosodium glutamate induced oxidative stress and excitotoxic brain damage in rats. Indian. J. Clin. Biochem. 28(3):292-298.

18. TANIDEH, N.; TAVAKOLI, P.; SAGHIRI, M.A.; GARCIAGODOY, F.; AMANAT, D.; TADBIR, A.A.; SAMANI, S.M.; TAMADON, A. 2013. Healing acceleration in hamsters of oral mucositis induced by 5-fluorouracil with topical Calendula officinalis. Oral. Surg Oral Med Oral Pathol Oral Radiol. 115(3):332-338.

19. WEI, Z.; ZHOU, E.; GUO, C.; FU, Y.; YU, Y.; LI, Y.; YAO, M.; ZHANG, N.; YANG, Z. 2014. Thymol inhibits Staphylococcus aureus internalization into bovine mammary epithelial cells by inhibiting NF- $\kappa \mathrm{B}$ activation. Microb. Pathog. Feb 28. [E-pub ahead of print].

Recibido: Agosto 28 de 2013

Aceptado: Abril 17 de 2014

Como citar:

Leal, M. 2014. Eficacia antibacteriana de extractos de plantas: aplicación clínica en mastitis bovina. Rev. U.D.C.A Act. \& Div. Cient. 17(1): 179-187. 
